\title{
Self-regulation from Emotive Feedback a Catalyst for Creative Task Appraisals in Design Education
}

\author{
T. Prasad-Mukhopadhyay, J. Ruiz-Pinales, R. Guzmán-Cabrera \\ Universidad de Guanajuato campus Irapuato-Salamanca, \\ DICIS, Guanajuato, Mexico
}

\begin{abstract}
We examined self-reports on performance of a group with untutored, unconstrained assignments (without external feedback) and contrasted it with 'control' performers in tutored sessions (with external feedback) to check if emotive self-regulation, based on participants' auto-feedback perceptions generate a better product trajectory. Does positive self-feedback work well and influence creative strategy in a positive way, just as proponents of 'emotional intelligence' advocate? Thus, could emotive self-feedback either reinforce or supplant conventional tutoring with external feedback signals in design schools. A brainwave entrainment was carried out to measure energy output and compare with self-reports during given intervals of the assignment. Results indicate presence of a reliable self-regulatory mechanism in which emotive-cognitive reflexes produces sufficient feedforward for task appraisal.
\end{abstract}

Keywords. Self regulation, emotive feedback, creative task.

\section{Introduction}

Research on self-feedback and regulation has generally derived from two directions: first in line with precepts of motivational studies of Rogers and Freiberg [1] and Csikszentmihalyi [2]. For Rogers and Freiberg, as well as Cszikszentmihalyi, the creative process uniquely elicits heightened attention and flow experiences - which together endorse the effects of emotive self-regulation $[3,4]$ that we are studying here, namely the psychological process of feedback and its intimate relation to selfregulatory resolutions of task.

Any design act will probably require emotional satisfaction as much as a recognition of successful implementation of techniques [5,6]. Subliminal (or intrinsic) feedback is shown also to act like a psychological rudder [7]. This feedback system was demonstrated in terms of feedback for individual learners that specifically promotes "self-regulation" [7, 8]. A combination of emotional feedback and 'self-regulation' may generate sufficient impetus for problem-solving moves and for finishing the task at hand [9].

The general relation between emotions and creativity have to be recognized before defining the role of self-induced motivations by activation and harnessing the creative person's mood states. Self-induced emotive regulation of performance, especially in the context of creativity, has been discussed in terms of intrinsic versus environmental 
factors in development of artistic abilities [10]. It is believed that the creative person has inner strengths and potential of creativity. For some investigators a basically causal paradigm which relates emotive satisfaction to performance explains creativity [11]. This explains the kind of achievement-oriented behavioralism that evidently guides independently working artists [12].

Although Freud and later theorists like John-Stern [12] explained creative output more in terms of unconscious drives, it is now understood that such drives could be quantified. Following Stern's foundational thoughts on dynamic achievement consciousness as a guide for realizing creative goals, Renzulli suggested that multiple behavioral factors caused creative output and full productive lives for individuals [13].

Creativity has since by explained in terms of motivation and self-reflexive emotional control that suggested a further modification of Renzulli's dynamic causality thesis for a more multi-factor behavioral model which most importantly included a recognition of the importance and function of emotions and mood congruent situations for creative output.

In this paper, feedback experiences are compared for two groups of participants, 'experimental' and 'control' with the purpose of understanding how emotional appraisals of one's performances causes direct behavioral changes in creative people, especially media artists. Research has shown how emotion is known to impact behavior in both direct and mediated ways: but especially by retrospective appraisal of actions and by stimulating further actions in a conscious manner. Given the fact that automatic and controlled behaviors [14] are both impacted by emotive feedback, or specifically mood appraisals, we chose to identify if self-induced mood appraisals are sufficient for maintaining or enhancing (or diminishing) creative performance, especially if the feedback was not derived externally.

In classical terms this is also known as the 'nature' versus the 'nurture' debate [14], the search for the fact if creativity and innovation could be more a matter of selfrecognition and 'nature'. The proposition has given birth to what Wei-Chen and colleagues [14] identifies as 'achievement-oriented' theories of creative behavior. On the whole the debate on intrinsic abilities may be studied in this classical context. At least some influential thinkers like Langer and Terman have emphasized on creative intelligence and IQ [11]. Facts show that individual creativity may be enhanced if the right environmental factors are available [15]. Giftedness may be a matter of potential but on the whole self-induced mechanisms of acquisition and realization of creative performances need to be discovered and studied [16]. What precisely are the results of an affective self-feedback mechanism that inspires creative people? How could selfassessment, conscious or otherwise, lead to increased levels of performance and satisfaction in creative performers?

\section{Related Work}

Yet, affect and emotions are always involved and integrated in the task - like a simultaneous circuit at work. Whether visual simulation (as also audio) depends solely on 
learning by means of prototypes or model emulation as mentioned above [17], or also on mood-congruent situations [18], is of the essence in this paper, although a larger number of studies already indicate in favor of recognizing the latter [19]. It has been observed generally that positive emotions benefit learning processes and outcomes [20].

Negative emotions such as anxiety have been interrelated with a lack of or discontinued motivation [21] and positive emotions such as pleasure and self-esteem were observed with high level of motivation [18]. There is an overt need of feeling an impulse, as it guides the designer to imagine and represent newer forms and entities. Therefore, in creative tasks, as opposed to logical reasoning, feeling and motivation, and consequently the sense of uninhibited freedom - or freedom from constraints - is a key factor. Students of arts and design, like their counterparts in other creative thinking processes like conceptual learning, also need a broader positive energy to perform better and achieve goals $[18,22]$. In more market-situated contexts apprentices develop their own skills by monitoring what they are learning and by comparing it to existing models that offer aural or visual precepts [23]. Van Moer proposes so far as to evolve an experience-based visual arts learning process, like John Dewey's classic thesis that learning art should ideally depend on individual experience, rather than mandatory advisory intervention [24]. There is a growing consensus on the role of 'self-regulated' learning for students [25], which lays emphasis on the way budding artists are inspired on their own to learn and improvise [23]. There are contrary studies highlighting the facilitatory effect of advisor interactions on students' learning. But a changing digital culture scenario implies more openness toward disinhibited factors of learning. Self-regulated design learning could be related to a student's inner experiences and may constitute a pillar of educative processes. Consider the ideal scenario for a digital arts student. Any learner needs to be free, driven (or motivated), and creative but not uninformed or misguided. As one tries to evolve a certain design one gets to be receptive to pre-existing patterns and images. But that is not all. A learner's resolve is also bound in by her 'feelings', which include subliminal (intrinsic) resources of motivation. Informal freedom of spirit and self-initiated motivation should thus be a key ingredient for this course of simulations, as has been claimed [22]. Again, studies have indicated how positively-valenced emotion facilitates conceptual learning [19]. Also, how "emotional intelligence" facilitates learning has been already studied [26]. In other cases, researchers have identified neuro-affective integration as the key factor for effective, wholistic learning [27]. But detailed analysis on how emotions may motivate students of digital design is therefore studied here. In digital art emotion may be assumed to play a very crucial role as both design and multimedia expressions employ things like imagination, feelings and desirability [28].

\section{Methodology}

In non-art contexts this is known as the development of "self-efficacy" in education, now for a long time [22]. We however wished to study the probable success of selfefficacy in context of self-regulated design, in untutored or minimally interventional 
training scenarios. This is because we wanted to find out if such contexts of creative expression eliminate external feedback and allows participants to rely on their own intuitions and sense of motivation associated with it. Innovation and performance are priorities for any design student. But how could student-interns perform well in market-oriented economies where demand and collective preference compromises individual innovations? It has been suggested that freedom from residual classroom pedagogies and use of game like interactive strategies could contribute to efficient, better and more enjoyable art education. In the experiment conducted here we tried to analyze this for the digital arts education scenario.

The experiment was based on the flowchart, see Figure 1, for a more selfmotivated design education of the kind promoted by the more fundamental studies. The fact that emotive intelligence is involved in design strategies was thus adopted as a requisite for understanding the role of emotive feedback on creative practices.

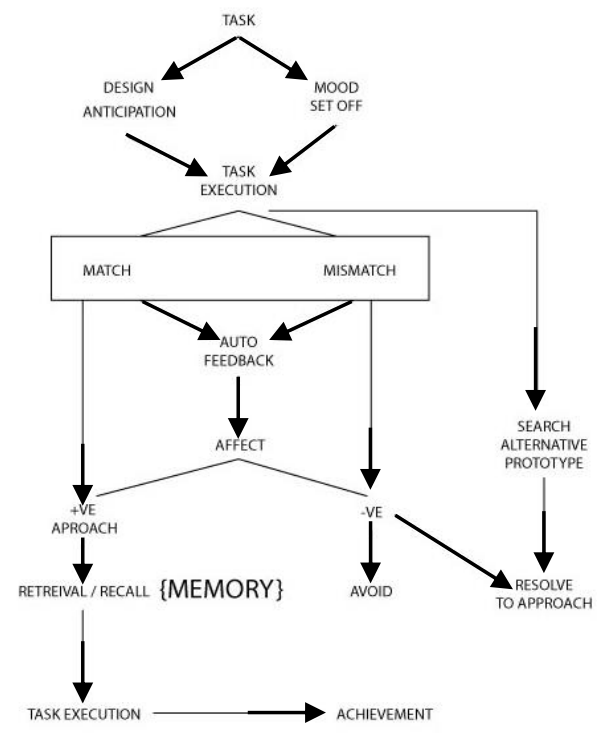

Fig. 1. Flowchart for a dualistic affective cognitive design learning activity based on preexisting research on creative processes and neuroscientific evidences of the role of emotions.

The experiment was conducted with aspiring artists, mostly students in digital arts and disciplines related to design $(n=20)$. Participants were in the age range of 19 to 23 , and all had prior experience in digital arts creation. Participants were beginnerdesigners and were selected on the basis of knowing basic software use skills. Also, digital arts curricula generally include learning or doing art projects on a variety software. Secondly, students were selected for a variety of software preferences.

Participants were invited to draw, or photoshop images or illustrations of their choice. Brainwave BCI equipment was fitted to their heads to accomplish the given task. Whereas participants in the Experimental group were free to act on their own mood feedbacks, generated in the creative process, control participants were subjected 
to normal teaching scenarios with feedback coming from a tutor or other expert in the field, thus conditioning their own sense of emotive satisfaction with task appraisals during the period of the experiment.

The first participants $(n=9)$ were tested with the EPOC-EEG hardware. The rest (11), were maintained as "control' and allowed to proceed only with external feedback or instructions as would be appropriate in normalized scenarios of design pedagogy. A simultaneous brainwave graph was recorded during the performance of said tasks. Brainwave activity for the same participants were checked against findings based on conscious semantic responses to the level of 'emotive satisfaction' and the sense of regulatory 'ability' experienced by participants.

To obtain cognitive data, a Brain-Computer Interface (BCI) device was used to capture brain signals during performance of tasks. The Emotiv-Epoc headset (Figure 4-a) has 14 EEG channels (electrodes). The distribution of sensors in the headset is based on the international 10-20 electrode placement system with two sensors as reference for proper placements on the head. Data mainly from 4 channels were used: AF3, F7, FC6 and AF4 (Figure 4-b). These 4 channels were chosen on the basis of their recognized association with high concentration and activity for creative or problem-solving tasks.

Electrical brain signals are obtained through noninvasive measures. Signal acquisition methods are mainly employed to observe spontaneous brain activity based on the electrical activity of signals.

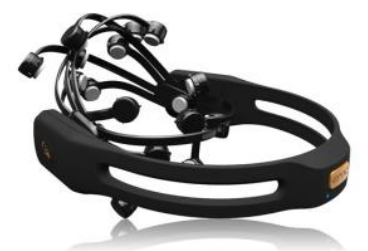

Fig. 2. (a).

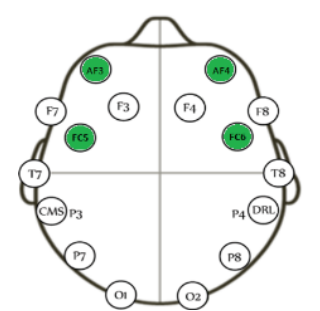

Fig. 2. (b).

Fig. 2. Emotiv-Epoc: (a) headset; (b) headset electrode arrangement.

Once the signals are captured, they are filtered with the purpose of separating them into beta and gamma.

When signals are acquired, generally, they are contaminated by noise and artifacts. Several techniques can be employed to remove noise and artifacts and identify the true signal. Feature extraction is done after noise is removed from the raw signal. 
Feature extraction techniques emphasize essential characteristics of the signal and its relation to biomedical events. In our case we used the Empirical Mode Decomposition (EMD). EMD is proposed as the fundamental principle of the Hilbert-Huang transform (HHT). The Hilbert Huang transform is carried out, so to speak, in 2 stages. First, we use the EMD algorithm: in the second stage the instantaneous frequency spectrum of the initial sequence is obtained by applying the Hilbert transform to the results of the previous step.

The HHT allows us to obtain the instantaneous frequency spectrum of nonlinear and non-stationary sequences. These sequences can consequently also be dealt with by using EMD. The signal obtained is not continuous in time. 7680 discrete values are recorded per minute at a sampling frequency of $128 \mathrm{~Hz}$. The signal is broken down into 22 signals (modes), which added together allow us to recover the original signal. This decomposition helps us calculate the energy in each time interval.

To separate the signals in the ranges of beta and gamma waves, the Hilbert frequencies are separated on the following basis: Beta 12 to $39 \mathrm{HZ}$, with an optimal \pm 16 $\mathrm{Hz}$ ideal range for creativity [3]. Gamma Range is considered to manifest over $40 \mathrm{~Hz}$ [3]. The energies are added in each mode for beta and gamma in the corresponding time interval. Simultaneous presence of higher beta and gamma should indicate more emotive satisfaction (arousal) and creative flow.

Higher energy output should be consistent with stress and concentration factors, higher gamma with more harmony. Supragamma levels of \pm 70 indicate emotive finésse in task execution, commonly associated with artistic competence. The betagamma distribution for these channels are more significant in so far as they reflect typical creative states.

\section{$4 \quad$ Results and Discussion}

In order to have an idea of how these signals are visible and therefore available for interpretation (as in Figure 3), the spectrogram obtained for a participant corresponding to the control group is shown. In this case it is for the band width of the beta signal, which ranges from 12 to $40 \mathrm{~Hz}(12 \leq \beta \leq 40 \mathrm{~Hz})$. Yellow indicates very strong activity, as a co-efficient of power for the frequency. Stronger yellow bands in the 10$20 \mathrm{~Hz}$ range indicates ideally high creative behavior, the optimal range being $16 \mathrm{~Hz}$ as is indicated in the literature.

To obtain the signals in the beta and gamma range from the signals caught on respective pre-frontal sensors of the Brainwave BCI the EMD (empirical mode decomposition) method of extraction is applied and the value of the frequency then obtained from the Hilbert-Huang transform. The result of this process is shown in Figures 3 and 4 . The Hilbert frequencies are separated using a $\beta$ band pass filter and a high pass filter for $\gamma$. 
Self-regulation from Emotive feedback a Catalyst for Creative Task Appraisals in Design Education
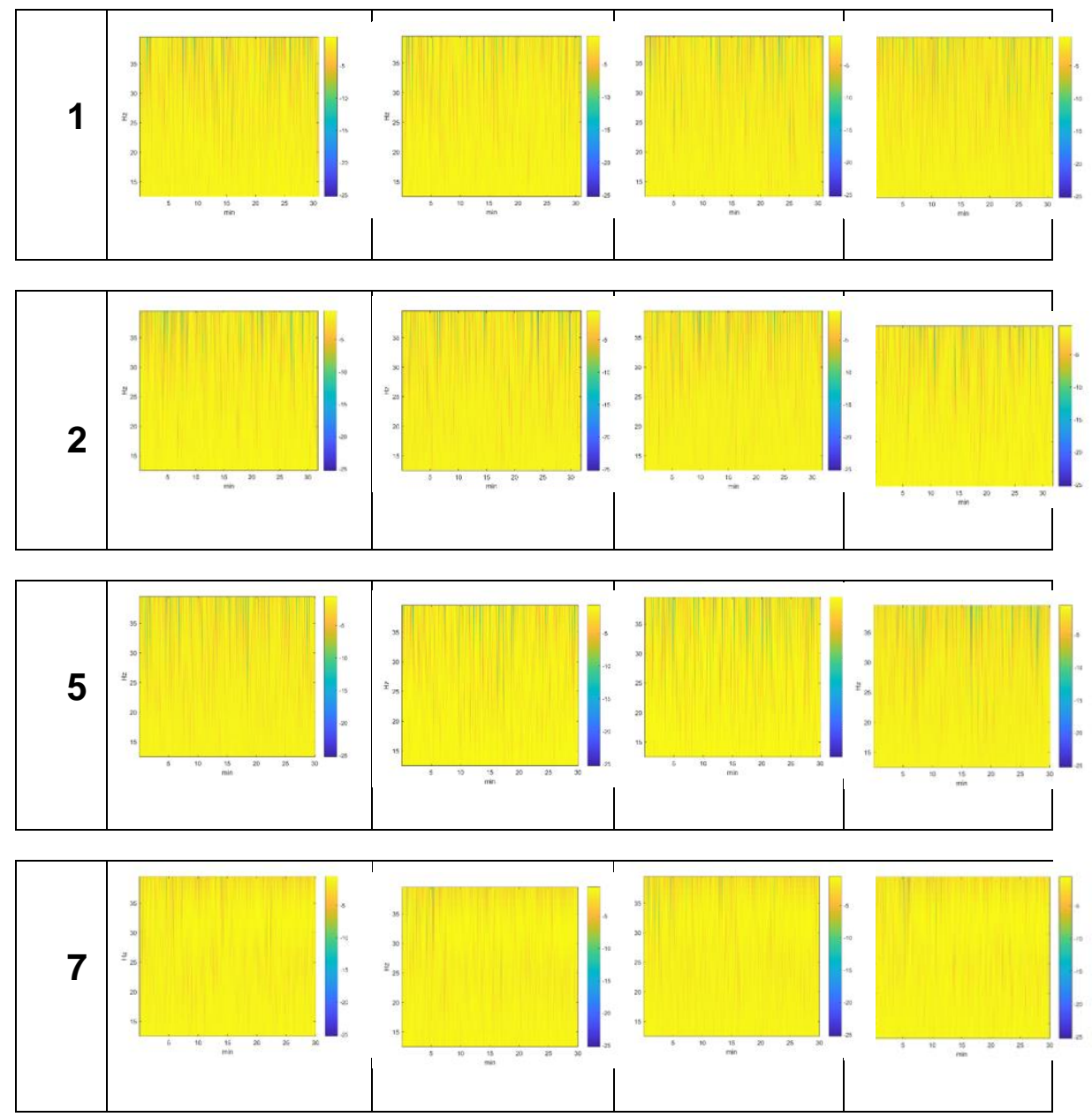

Fig. 3. Beta range signals in sample participant in the Experimental (self-motivated feedback) group. Notice that at least 4 participants $(1,2,5,7)$ demonstrate very strong, i.e. yellow bands in the $\pm 16 \mathrm{~Hz}$ range, or beta wave activity for concentration and innovation.

Figure 4 shows, for the same selected participant, the spectrogram corresponding to the gamma signal $(40 \leq \gamma \leq 90 \mathrm{~Hz})$.

We can see in Figures 3 and 4 a significant variation in color. A higher value in frequency represents greater emotional activity: so, for example $90 \mathrm{~Hz}$ is more emotionally proactive with task appraisal scenarios. Figure 4 shows that in the same group of participants as in Figure 3 above there are yellow bands, less prominent, but definitely indicative for a very high frequency close to gamma range frequency. The higher, closer to gamma range indicators, though less regular in the spectrogram, represent achievable peaks in self-motivated participants. 


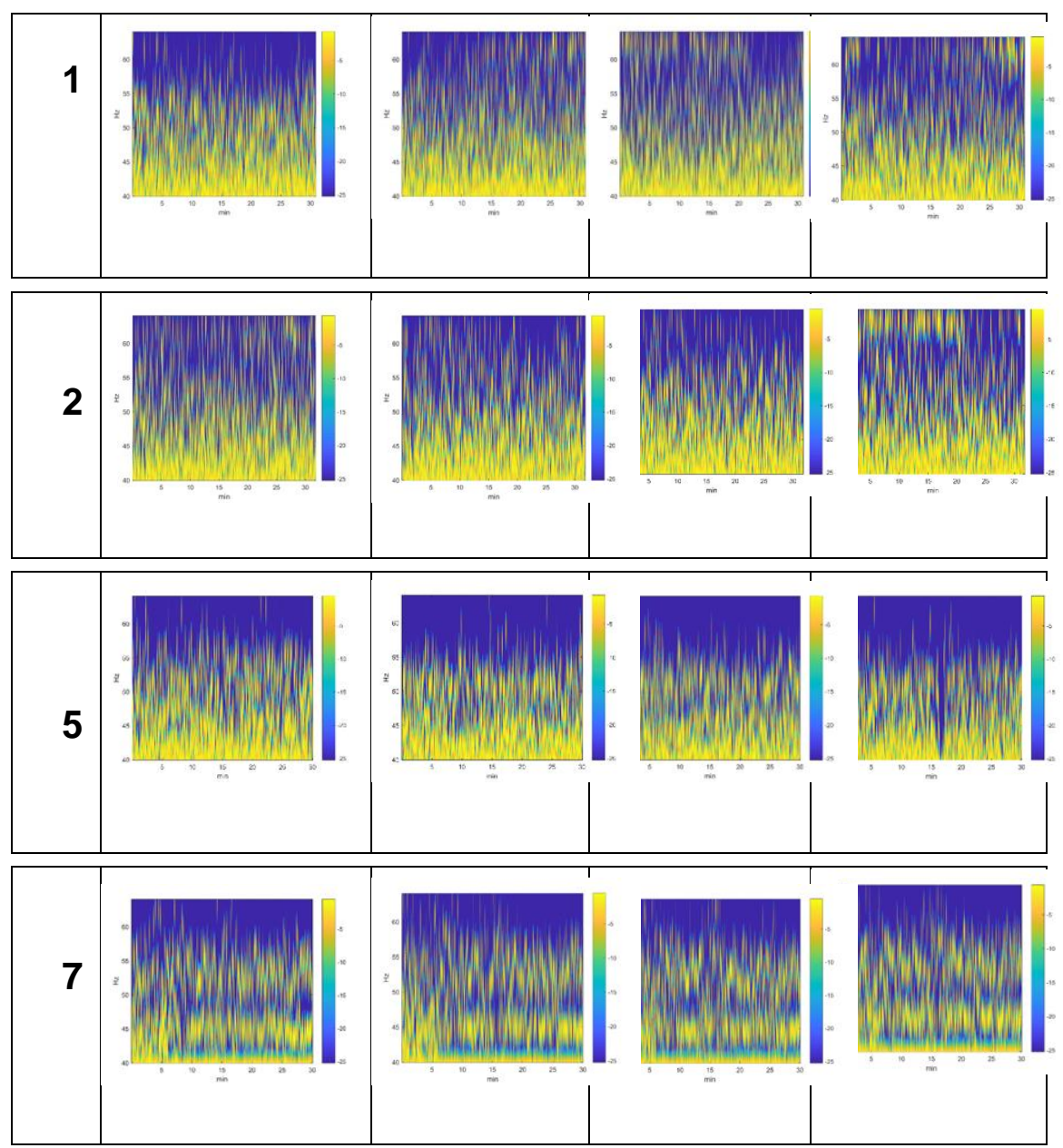

Fig. 4. Gamma signal spectrography for sample participant in same experimental group as in Figure 3 above.

Tables 1 and 2 show the sums of the energies grouped in periods of 5 minutes. The summation helps in analysis of the activity of each participant in the specified intervals during the trajectory of the experiment.

The presence of a possibly normative self-motivational feedback, deriving from successful 'emotive feedback' and 'self-regulation' may be seen reflected in the Fourier spectrogram analysis of at least $44 \%$ of participants in the experimental group as contrasted to only $36 \%$ of participants in the control or external feedback group (see Figure 5 and 6). A sum of the average frequencies recorded for each candidate in each category was considered for statistical analysis. A distinctly high beta wave peak in unconscious Epoc-EEG brainwave BCI was evidently found to be the trend in both experimental and control group participants. 
Table 1. Average energy (in picojoules) for all four individual channels usually considered for measuring creativity in participants of experimental group.

\begin{tabular}{|c|c|c|c|c|c|c|c|c|c|c|c|c|c|c|c|}
\hline \multirow[b]{3}{*}{$\mathbf{N}$} & \multicolumn{15}{|c|}{ EXPERIMENT (Without Training) } \\
\hline & & & & \multicolumn{6}{|c|}{$\begin{array}{c}\text { Beta (AF4+F7+AF3+AF6) } \\
\text { (pJ) }\end{array}$} & \multicolumn{6}{|c|}{$\begin{array}{c}\text { Gama (AF4+F7+AF3+AF6) } \\
(p J)\end{array}$} \\
\hline & Age & G & Ca & $5 \mathrm{~min}$ & $10 \mathrm{~min}$ & $15 \mathrm{~min}$ & $20 \mathrm{~min}$ & $25 \mathrm{~min}$ & $30 \mathrm{~min}$ & $5 \mathrm{~min}$ & $10 \mathrm{~min}$ & $15 \mathrm{~min}$ & $20 \mathrm{~min}$ & $25 \mathrm{~min}$ & $30 \mathrm{~min}$ \\
\hline 1 & 21 & M & DA & 4.1 & 3.3 & 21.3 & 2.8 & 4.6 & 2.7 & 0.6 & 0.5 & 0.7 & 0.7 & 0.6 & 0.8 \\
\hline 2 & 22 & M & DA & 30 & 1.2 & 1.6 & 3.5 & 6.4 & 2.7 & 1.5 & 0.6 & 0.7 & 1.1 & 1.4 & 0.6 \\
\hline 3 & 23 & $\mathrm{~F}$ & DA & 2.3 & 50.1 & 12.2 & 10.5 & 6.1 & 27.1 & 0.2 & 18.7 & 0.4 & 0.3 & 0.2 & 0.6 \\
\hline 4 & 20 & $\mathrm{~F}$ & DA & 10.4 & 28 & 33.2 & 23 & 16 & 18 & 0.3 & 1.1 & 1.3 & 0.6 & 0.6 & 0.6 \\
\hline 5 & 22 & $\mathrm{~F}$ & M & 7.3 & 11.2 & 12.1 & 57.9 & 34.2 & 28 & 0.3 & 0.5 & 0.5 & 0.6 & 0.3 & 0.5 \\
\hline 6 & 25 & $\mathrm{~F}$ & DA & 9.2 & 16 & 18 & 11 & 19 & 9.3 & 9.3 & 9.7 & 9.2 & 1.8 & 18. & 7.9 \\
\hline 7 & 24 & $\mathrm{~F}$ & DA & 33.2 & 28.7 & 87.4 & 87.9 & 121.4 & 170.8 & 5.8 & 6.4 & 13.9 & 15.5 & 23.5 & 25 \\
\hline
\end{tabular}

DA: Digital Arts, M: Mechatronics

Table 2. Average energy for all four individual channels usually considered for measuring creativity in participants of control group.

\begin{tabular}{|c|c|c|c|c|c|c|c|c|c|c|c|c|c|c|c|}
\hline & \multicolumn{15}{|c|}{ CONTROL (With Training) } \\
\hline & \multirow[b]{2}{*}{ Age } & \multirow[b]{2}{*}{ G } & \multirow[b]{2}{*}{$\begin{array}{l}\mathrm{c} \\
\mathrm{a}\end{array}$} & \multicolumn{6}{|c|}{$\begin{array}{c}\text { Beta (AF4+F7+AF3+AF6) } \\
(p J)\end{array}$} & \multicolumn{6}{|c|}{$\begin{array}{c}\text { Gama (AF4+F7+AF3+AF6) } \\
\text { (pJ) }\end{array}$} \\
\hline & & & & 5 & 10 & 15 & 20 & 25 & 30 & 5 & 10 & 15 & 20 & 25 & 30 \\
\hline & 24 & $F$ & $\begin{array}{l}\text { D } \\
\text { A }\end{array}$ & $\begin{array}{c}257 . \\
4\end{array}$ & 31.4 & 73.5 & 23.3 & 48.3 & 21.4 & 27.1 & 10.1 & 9.7 & 6 & 2.2 & 1.5 \\
\hline & 29 & M & $\begin{array}{l}\text { D } \\
\text { A }\end{array}$ & 61.8 & 14.9 & 12.4 & 52.8 & 14.5 & 18.8 & 10.4 & 6 & 5.3 & 4.8 & 5.3 & 6.4 \\
\hline \multirow[t]{6}{*}{3} & 21 & M & $\begin{array}{l}\text { D } \\
\text { A }\end{array}$ & 22.9 & 2.8 & 3 & 3.6 & 25 & 23 & 0.5 & 0.2 & 0.3 & 0.3 & 0.3 & 0.3 \\
\hline & 25 & $\mathrm{~F}$ & $\begin{array}{l}\text { D } \\
\text { A }\end{array}$ & 16.4 & 275.8 & 3.1 & 51.9 & 101 & 2.5 & 1.4 & 33.2 & 1 & 1.7 & 1.3 & 0.6 \\
\hline & 23 & $\mathrm{~F}$ & $\begin{array}{l}\mathrm{D} \\
\mathrm{A}\end{array}$ & 9.0 & 10.7 & 9.5 & 13.4 & 10.1 & 11.4 & 0.3 & 0.3 & 0.2 & 0.2 & 0.2 & 0.2 \\
\hline & 22 & M & $\begin{array}{l}\text { D } \\
\text { A }\end{array}$ & 51.8 & 4.6 & 68 & 4 & 2.8 & 9.4 & 11.7 & 0.6 & 17.7 & 0.5 & 0.4 & 0.4 \\
\hline & 22 & $\mathrm{~F}$ & $\begin{array}{l}\text { D } \\
\text { A }\end{array}$ & $\begin{array}{c}291 . \\
3\end{array}$ & 126.3 & 39 & 192.4 & 36.1 & 16.8 & 27.3 & 17.4 & 9.2 & 5.9 & 7.5 & 2.3 \\
\hline & 23 & $\mathrm{~F}$ & $\begin{array}{l}\text { D } \\
\text { A }\end{array}$ & 6.8 & 8.3 & 10 & 9.2 & 9.2 & 8 & 0.2 & 0.2 & 0.3 & 0.3 & 0.3 & 0.3 \\
\hline 0 & 21 & M & $\begin{array}{l}\text { D } \\
\text { A }\end{array}$ & 3.6 & 4.6 & 3.9 & 3.3 & 4.2 & 4.7 & 0.6 & 0.5 & 0.4 & 04 & 0.5 & 0.8 \\
\hline 1 & 26 & $\mathrm{~F}$ & EE & 14.6 & 17.6 & 14.8 & 15.3 & 32.1 & 21.6 & 0.6 & 0.9 & 0.6 & 0.7 & 2.3 & 1.1 \\
\hline
\end{tabular}

DA: Digital Arts, EE: Electronics Engineering

The frequency data was adopted for both experimental and control groups involved in self-regulatory feedback and external tutored feedback for creative trajectories respectively. Of all channels AF4, AF3 F6 and F7 were considered for focus and creative, i.e. problem-solving task appraisals (Jansen 2005; Herrington et al 2005; Gruzlier 2009). Beta radiation studied for pre-frontal problem solving areas indicate activation and level of focus or absorption of participants in their work. 


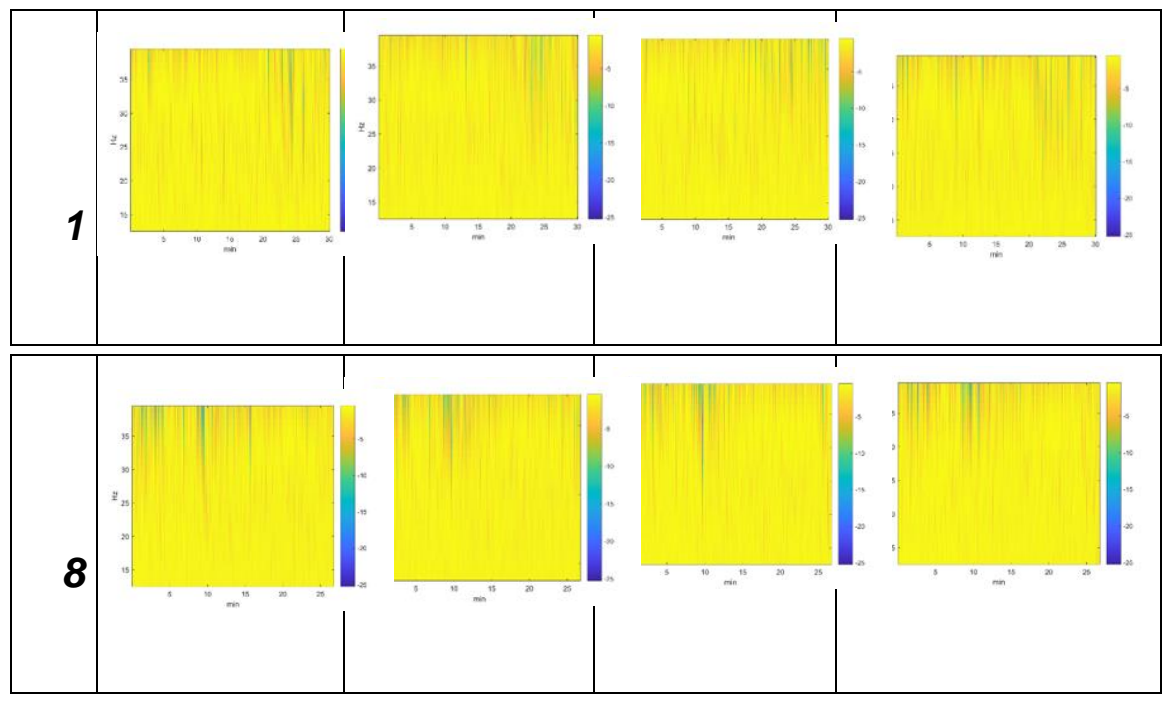

Fig. 5. High yellow band peaks at the $\pm 16 \mathrm{~Hz}$ beta frequency range is also visible for Control participants who work on the basis of external feedback. But the number of participants with decidedly thick yellow band (i.e. high energy) output is less than in Experimental group, and also less evenly distributed.

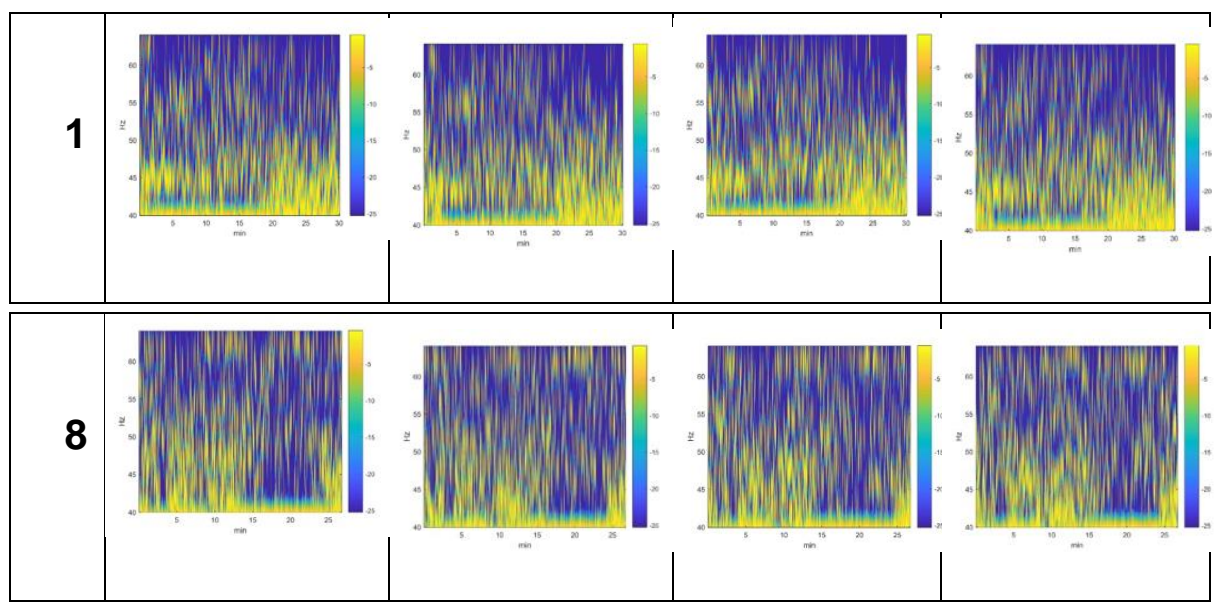

Fig. 6. High yellow band peaks at the $\pm 90 \mathrm{~Hz}$ Gamma frequency range is also visible for Control participants who work on the basis of external feedback. But the number of participants, as in Figure 5 above is less than the number of participants in the experimental group and also less evenly distributed.

Of the $44 \%$ of higher Beta and Gamma activity as recorded for the self-regulated experimental group participants 1, 2, 7 in the experimental group demonstrate high Gamma wave activity in all PFC terminals, notably AF4, F6 and F7 in the total 30minute segment. (Figure 3). Participant 2 reflects exclusively high peaks for AF4 and 
F7. Participant 5 demonstrates more sporadic creative peaks for both Beta and Gamma.

\section{$5 \quad$ Limitation and Conclusion}

On the basis that behavior of the control and experimental groups is the same (and assuming that high energy beta and gamma values would generally reflect the same values in contexts of self-regulatory and external feedback) we observe that performance indicators for brainwave have no significant difference as far as brain activity is concerned ( $\mathrm{p}$-value $>0.05$ ).

Contrarily positive self-feedback could indicate towards better flow results for dedicated artists working on self-instruction reliance. There are preponderant high peak outputs, indicative of tranquility and flow for self-motivated and self-regulated creativity, though this may not be a universal rule in creative behavior. Design learning is definitely fostered by self-induced positive emotions.

We know how feedback strategies influence creative and meditative practices (Peper 2012). In this article however we have tried mainly to focus on feedback generated by learner-artists whose work requires imagination, freedom and emotional happiness or satisfaction as distinguished from less emotionally dependent tasks like mathematical problem-solving. Comparing the brainwave functions for the same timeintervals we tend to observe two things. First, that minimally interventional, selfinduced motivation provides good impetus for creativity in digital art contexts and is not significantly different from scenarios in which pedagogy, collective inputs, external feedback and limitations imposed from outside are included in the practice. We also observed that instructions and extraneous interventions do not necessarily create a more stable maintenance curve for 'control' participants. The fact that we could have self-sufficient intuitive feeling, especially for highly innovative tasks like creative design, makes us reconsider the necessity of having a free and self-reliant educational environment. The social consequences of implanting such an environment may be desirable in many cases, especially where tutorial intervention is not in emotional and imaginative sync with the performer. In the digital age young learners are often more tech-savvy and advanced in their exposure to a wide variety of media. Assessing the important role played by self-motivated actions in our learning and executive experiences are important and may show us a path out of traditional classroom spaces.

\section{References}

1. Rogers, C. R., Freiberg, H. J.: Freedom to learn (1994)

2. Csikszentmihalyi, M.: Flow and the psychology of discovery and invention. New York: Harper Collins (1996)

3. Runco, M. A., Plucker, J. A., Lim, W.: Development and psychometric integrity of a measure of ideational behavior. Creativity Research Journal, 13(3-4), 393-400 (2001) 
4. Heo, M. S., Cheon, M. J.: An empirical study on the relationship between role stress and personal creativity: The mediating roles of creative self-efficacy and personal initiative. The Journal of Information Systems, 22(2), 51-83 (2013)

5. Zimmerman, B. J., Kitsantas, A.: Developmental phases in self-regulation: Shifting from process goals to outcome goals. Journal of educational psychology, 89(1), 29 (1997)

6. Hattie, J., Timperley, H.: The power of feedback. Review of educational research, 77(1), 81-112 (2007)

7. Winner, E.: Development in the Arts: Drawing and Music. Handbook of Child Psychology. DOI: 10.1002/9780470147658.chpsy0220 (2007)

8. Russ, S. W.: Affect and creativity: The role of affect and play in the creative process. Psychology Press (1993)

9. Al-kreimeen, R. A.: The Relationship between Individual Creativity and Self-RegulationFrom Grade Nine Students Viewpoints in Jordan. International Proceedings of Economics Development and Research, 78, 85 (2014)

10. Heller, K. A., Mönks, F. J., Subotnik, R., Sternberg, R. J. (Eds.).: International handbook of giftedness and talent. Elsevier (2000)

11. Terman, L. M.: The discovery and encouragement of exceptional talent. American psychologist, 9(6), 221 (1954)

12. Stern, S.: The relationship between human resource development and corporate creativity in Japan. Human Resource Development Quarterly, 3(3), 215-234 (1992)

13. Renzulli, J. S.: What is this thing called giftedness, and how do we develop it? A twenty five year perspective. Journal for the Education of the Gifted, 23(1), 3-54 (1999)

14. Wei-Chen, H., Smith, T. J., Smith, M. C.: Design and usability assessment of a dialoguebased cognitive tutoring system to model expert problem solving in research design. British Journal of Educational Technology, 46(1), 82-97 (2015)

15. Gardner, H., Gardner, E.: Art, mind, and brain: A cognitive approach to creativity. Basic Books (2008)

16. Runco, M. A., Yoruk, S.: The neuroscience of divergent thinking. Activitas Nervosa Superior, 56(1-2), 1-16 (2014)

17. Stavridou, F., Kakana, D.: Graphic abilities in relation to mathematical and scientific ability in adolescents. Educational Research,50(1), 75-93 (2008)

18. Kim, C., Pekrun, R.: Emotions and motivation in learning and performance. In Handbook of research on educational communications and technology. pp. 65-75, Springer New York (2014)

19. Endrissata, N., Islamb, G., Noppeneya, C.: Visual organizing: Balancing coordination and creative freedom via mood boards. Journal of Business Research. DOI:10.1016/j.jbusres.2015.10.004

20. Pekrun, R., Goetz, T., Frenzel, A. C., Barchfeld, P., Perry, R. P.: Measuring emotions in students' learning and performance: The Achievement Emotions Questionnaire (AEQ). Contemporary Educational Psychology, 36(1), 36-48 (2011)

21. Artino, A. R., Stephens, J. M.: Academic motivation and self-regulation: A comparative analysis of undergraduate and graduate students learning online. The Internet and Higher Education, 12(3), 146-151 (2009)

22. Zimmerman, B. J.: Investigating self-regulation and motivation: Historical background, methodological developments, and future prospects. American educational research journal, 45(1), 166-183 (2008)

23. Ings, W.: Malleable Thought: The Role of Craft Thinking in Practice-Led Graphic Design, International Journal of Art \& Design Education, Volume 34, Issue 2, 180-191, DOI: 10.1111/jade.12013 (2015)

24. Van Moer, E., De Mette, T., Elias, W.: From Obstacle to Growth Dewey's Legacy of Experience-Based Art Education. International Journal of Art \& Design Education, 27: 43-52, doi: 10.1111/j.1476-8070.2008.00556.x (2008) 
Self-regulation from Emotive feedback a Catalyst for Creative Task Appraisals in Design Education

25. Haanstra, F.: Self-Initiated Art Work and School Art. International Journal of Art \& Design Education, 29: 271-282. doi: 10.1111/j.1476-8070.2010.01662.x (2010)

26. Spendlove, D.: A Conceptualisation of Emotion within Art and Design Education: A Creative, Learning and Product-Orientated Triadic Schema. International Journal of Art \& Design Education, Volume 26, Issue 2, 155-166. DOI: 10.1111/j.1476-8070.2007.00525.x (2007)

27. Clarken, R. H.: Wholistic education: Toward a definition and description. In Annual Meeting of the American Educational Research Association, San Francisco (2006)

28. Silvia, P. J.: Cognitive appraisals and interest in visual art: Exploring an appraisal theory of aesthetic emotions. Empirical studies of the arts, 23(2), 119-133 (2005) 